\title{
Mechanical Methods of Microencapsulation: A Review
}

\author{
K.CH.S. Saikiran ${ }^{1}$, Monisha Perli ${ }^{2 *}$, N. Sreedhar Reddy ${ }^{1}$ and N. Venkatachalapathy ${ }^{3}$ \\ ${ }^{1}$ IIFPT, Thanjavur, Tamil Nadu, India \\ ${ }^{2}$ Department of Applied Engineering, Vignan's Foundation for Science, Technology and \\ Research, Guntur, Andhra Pradesh, India \\ ${ }^{3}$ Food Engineering, IIFPT, Thanjavur, Tamil Nadu, India \\ *Corresponding author
}

\section{A B S T R A C T}

\begin{tabular}{|l|}
\hline Ke y w o r d s \\
$\begin{array}{l}\text { Micro encapsulation, } \\
\text { Wall material, Core } \\
\text { material }\end{array}$ \\
\hline Article Info \\
\hline $\begin{array}{l}\text { Accepted: } \\
\text { 10 October } 2018 \\
\text { Available Online: } \\
\text { 10 November } 2018\end{array}$ \\
\hline
\end{tabular}

Micro encapsulation is one of the promising technologies for the preservation of highly sensible components in several fields like medicine, drug and food processing industries. The technique of microencapsulation helps in preservation and storage of the products which also increases the shelf life; this made the technique more famous in various industries like food processing, pharmaceuticals, textiles, Biotechnology etc. Microencapsulation is the most useful preservative technique for spice industry as the technique helps in the keeping the quality of spices. The technique involves with two components, one is the wall material, which encapsulates the sensible components and the other is core material, a highly sensible component which is to be encapsulated by wall material. There were several methods for undergoing the process of microencapsulation like spray drying, fluidised bed coating (top spray, bottom spray and tangential spray) spinning disk, Pan coating etc. All these methods and the research works undergo with these methods were discussed briefly in this review.

\section{Introduction}

Microencapsulation is the method of enclosing the fine particles of one substance with the other substance in order to give small capsules called as micro capsules.

The micro capsules are spherical in shape and are covered by a uniform coating known as wall or shell. The material which is to be enclosed is called core material and the material which covers or surrounds the core material is called wall material or shell (Mali et al., 2013).
The definition of microencapsulation made its diversified applications to different foods. There are different classes of foods and every class can be encapsulated. The sensory attributes or sensory characters of foods are very important and out of these flavours is the most important attribute, by using microencapsulation technique the flavour can be retained easily. The microencapsulation depends on physical and chemical properties of the materials that are to be encapsulated. The core particles are then encapsulated in the micron-sized capsules of gelatine, plastic and wax. The material that is to be encapsulated i.e 
the core may be a crystal or it may be a suspension of solids. The micro encapsulation may be single layer or even in multiple layers based on the characteristics of the core material.

\section{History}

Firstly, in the year 1932, microencapsulation procedure was discovered by Dutch chemist "H.G. Bungenberg de Jong". The first commercial product using the technique of microencapsulation was launched by NCR of American in 1953. The technique of microencapsulation was not a new technology for food processing industry and by the history it was introduced in the mid of $20^{\text {th }}$ century.

The terms or materials used in encapsulation process

The entire microencapsulation is based on terms mainly they are the core material and wall material. The range of micro capsules is from micrometre to millimetre.

\section{Core material}

The material to be coated is called core material and examples of core materials are solids, liquids or a mixture of these such as dispersion of solids in liquids. Drugs, diluents, stabilizers and rate enhancers can also be core materials (Bansode et al., 2010) (Fig. 1-11).

\section{Wall material}

The wall material or shell or covering material, the prime function or the objective of wall material is to protect the core material.

The examples of wall material are gums, lipids, proteins, carbohydrates, cellulosesetc. The natural examples of core and wall materials are seeds and egg shell respectively (Snehal et al., 2013)

\section{Important characteristics of wall material}

1) Ability to seal and hold the active material or core material. 2) Non-reactivity of the coating material with the wall material. 3) Provide maximum protection to the coating material. 4) The wall material must be economical and it must be food grade substance. 5) Approved by controlling authority.

\section{Reasons for encapsulation}

1) Enhances the overall quality of food products. 2) Reduces the evaporation or transfer of the core material to the outside environment. 3) Superior handling of the active agent. 4) Provides the incorporation of vitamins and minerals. 5) Improved stability in final product and during processing. 6) Control release of the active components. 7) Masks the aroma, flavor, and color of some ingredient

\section{Advantages}

1) Microencapsulation is used in the areas where the drugs are to be delivered to the target sites. 2) It is also helpful in maintaining the desired concentration at the site of interest without any unwanted effects. 3) The solid microcapsules have the potential throughout the particle matrix for the controlled and timely release of drugs. 4) The microcapsules received much attention not only for the prolonged release of drugs but also for targeting the anti-cancer drugs to tumor

\section{Different mechanical methods involved in encapsulation}

The following are the different mechanical methods that are employed during the process of micro encapsulation. 1) Spray drying 2) Spray chilling 3) Fluidised bed coating 4) Spinning disc 5) Pan coating 


\section{Spray drying}

The spray drying process is the most economical process and the equipment is readily available in many industries and the technique of spray drying is also an oldest process. The particle size in spray drying ranges between $10-50 \mu \mathrm{m}$ and this process produces good quality particles. Spray drying is the continuous transformation of feed from a fluid state into dried particulate form by spraying the feed into a hot drying medium.

An emulsion is prepared by dispersing the core material, usually an oil or active ingredient immiscible with water; into a concentrated solution of wall material until the desired size of oil droplets are attained. The resultant emulsion is atomized into a spray of droplets by pumping the slurry through a rotating disc into the heated compartment of a spray drier. There the water portion of the emulsion is evaporated, yielding dried capsules of variable shape containing scattered drops of core material (Estevinho et al., 2013).

The products are the micro capsules are collected at product discharge of the spray dryer. There are different micro particles that are produced by using aqueous chemical methods, such particles can also be used for spray drying.

Research works on microencapsulation using spray drying technique

Characteristics of microencapsulated $\beta$ carotene formed by spray drying with modified tapioca starch, native tapioca starch and maltodextrin

This study was conducted by Jarunee Loksuwan (2007) in order to test the ability of wall materials for encapsulation. The wall materials used were Acid-modified tapioca starch, native tapioca starch, and malt dextrin.
These were tested for encapsulating the core material $\beta$-carotene, by spray drying technique.

Microencapsulation by spray drying of bioactive compounds from cactus pear (Opuntiaficus-indica)

In this study the core materials like bio active compounds of pulp and ethanoic extracts of cactus pear were encapsulated using maltodextrin or inulin. (Saenz et al., 2009)

Microencapsulation of avocado oil by spray drying using whey protein and malt dextrin

In this study the cold pressed avocado oil was encapsulated using whey protein alone or in combination with maltodextrin under different ratios (Bae and Lee, 2008).

Microencapsulation by spray drying ethyl caprylate in whey protein and carbohydrate wall systems

In this study ethyl caprylate was encapsulated using whey protein or in combinations with maltodextrin and corn syrup (Sheu and Rosenberg, 1995).

\section{Influence of emulsion composition and inlet air temperature on the microencapsulation of flaxseed oil by spray drying}

This study was conducted to check the effect of process parameters like temperature during micro encapsulation of flax seed oil by spray drying (Tonon et al., 2011).

Research works on microencapsulation using spray chilling technique

\section{Spray chilling}

The objective or the purpose of spray chilling is to produce a lipid coated active agent such 
that the micro particles are insoluble in water. The core and wall materials are selected and the mixture is atomised in to the cool air coming from the cooler whenever the mixture come in contact with the chilled air immediately the wall material will solidify and a protective coating is formed around the core material. There is no evaporation of water as there is no heat involved during the process. The particle size ranges from -20 to $200 \mu \mathrm{m}$

\section{Protection of Bifid bacteriumlactis and Lactobacillus acidophilus microencapsulation using spray-chilling}

The objective of the study was to produce solid lipid micro particles containing Bifidobacterium lactis and also to evaluate the produced particles (De lara et al., 2012).

Micro particle size control and glimepiride microencapsulation using spray congealing technology

In this study drug-free micro particles were produced using spray congealing process, by studying the effect of process parameters, like atomizer pressure, feed rate and size of the micro particles. (Ilic et al., 2009).

\section{Research works undergone using fluidized bed technique}

Coating of pharmaceutical powders by fluidized bed process. Microencapsulation Using Blend and Composite Latices of Copoly (Ethyl Acrylate-Methyl Methacrylate-2Hydroxyethyl Methacrylate (Ichikawa et al., 1994)

Top-Spray Fluidized Bed Coating: Effect of Process Variables on Coating Efficiency (Dewettinck and Huyghebaert, 1998).

Encapsulation of oil in powder using spray drying and fluidised bed agglomeration
Agglomeration tendency during top-spray fluidized bed coating with gums

\section{Fluidised bed coating}

The fluidised bed coating is also known as suspension coating. This technique is mainly used in pharmaceutical industries and now it is also employed in food industries because of its benefits. The principle involved in fluidised bed coating is that the liquid coating or wall material is sprayed on to the particles of core and the rapid evaporation helps in the formation of a protective layer on the active material or cores. TheCoating materials used in the process are Cellulose derivatives, lipids, protein derivatives, and starch derivatives. The particle size in this process is 20 to $1500 \mu$

The fluidized bed coating process is three types. They are 1) Top spray 2) Bottomspray 3) Tangential spray

\section{Top spray}

The classification of top spray, bottom spray and tangential spray are based on the direction in which the core material and wall material sprayed. In top spray the coating material is sprayed from the top to downwards in order to meet the core material which is ejecting from the bottom. The core material comes in contact with the wall material and there will be formation of protective covering around the core material. As the wall material is sprayed from the top there is increased encapsulation efficiency.

\section{Bottom spray}

Bottom spray fluidised bed coating is also known as as "Wurster's coater". The equipment consists of a coating chamber, cylindrical nozzle and a perforated bottom plate. The coating material is sprayed from the bottom such that the particles move upwards. 
Fig.1 Microcapsule with core and wall (Jyothi et al., 2012)

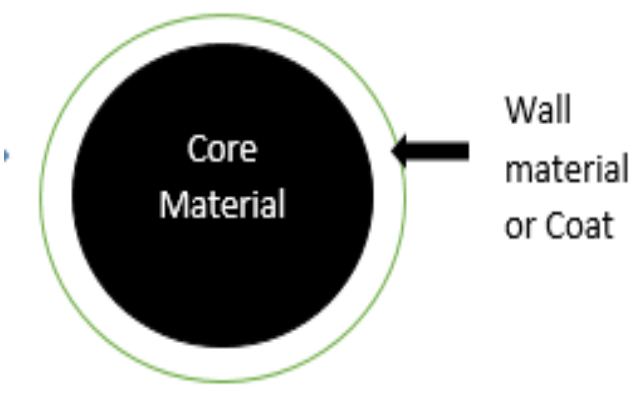

Fig.2 Microencapsulation process (Jyothi et al., 2012)
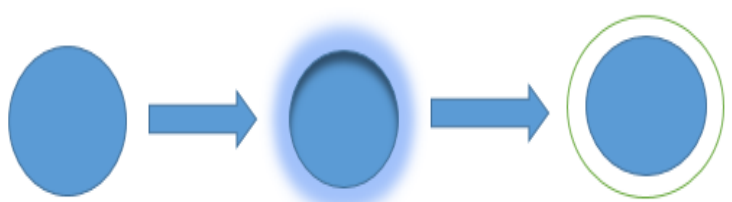

Fig.3 Spray drying equipment Technique

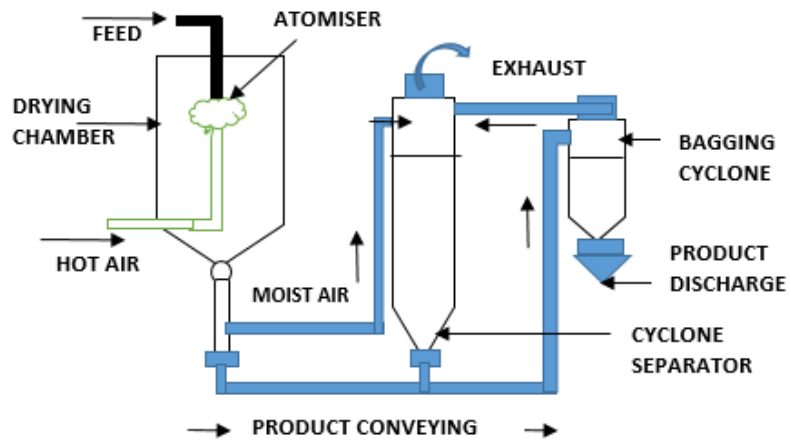

Fig.4 Encapsulation process in spray drying

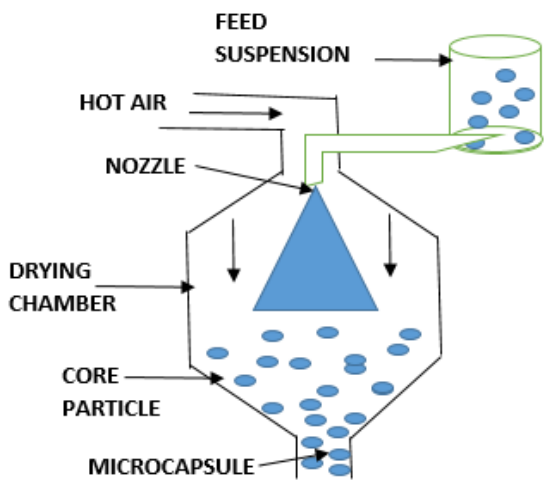


Fig.5 Encapsulation using spray chilling

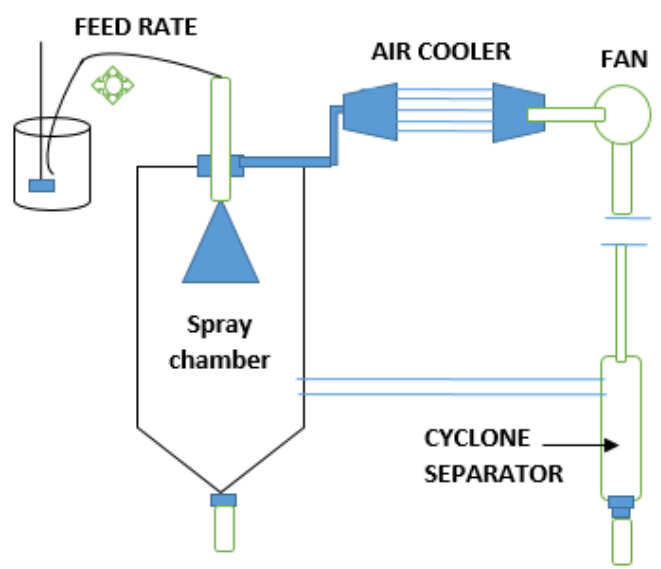

Fig.6 Encapsulation using top spray

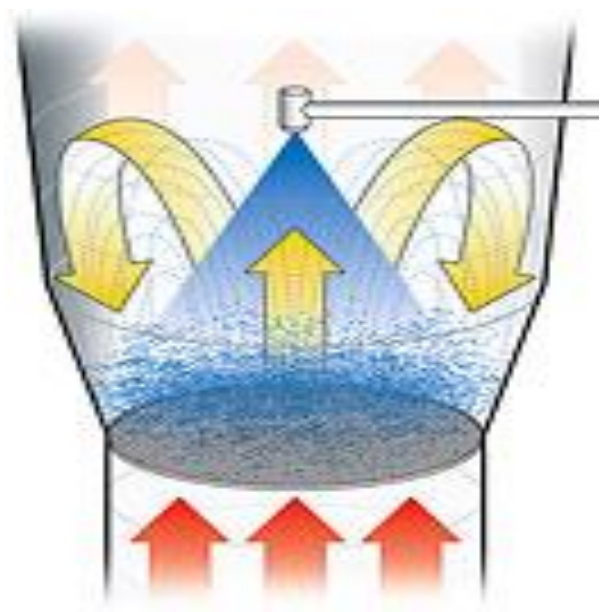

Fig.7 Bottom spray fluidised bed coating

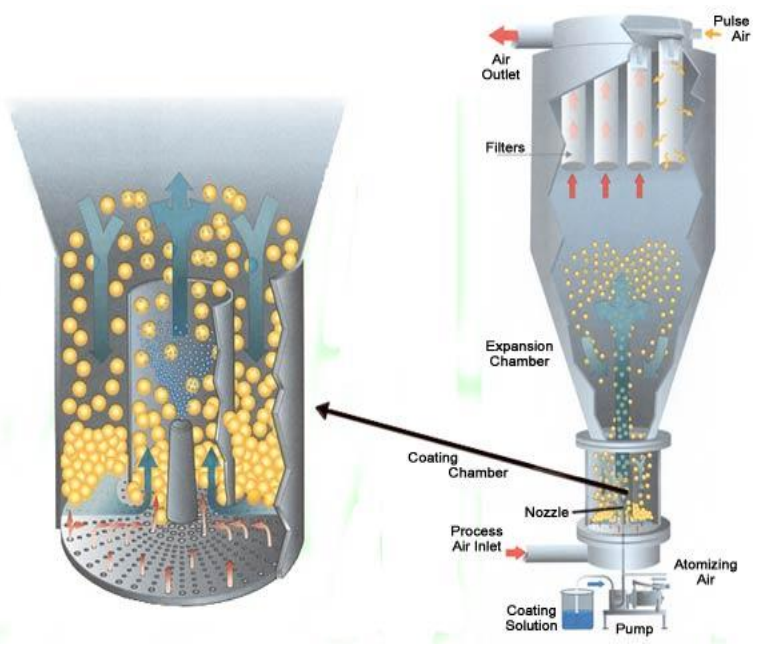


Fig.8 Tangential spray coating

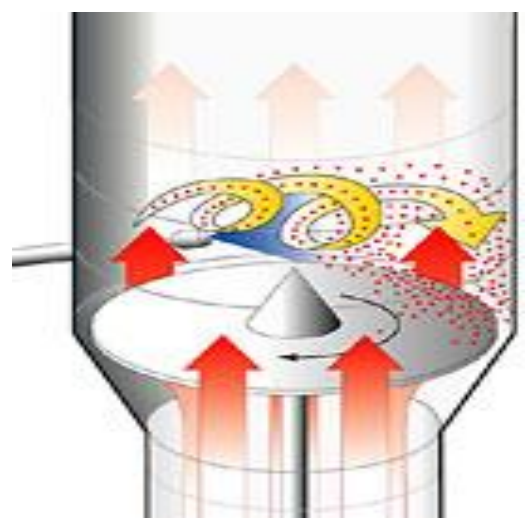

Fig.9 Encapsulation using spinning disk (Gharsallaoui et al., 2007)

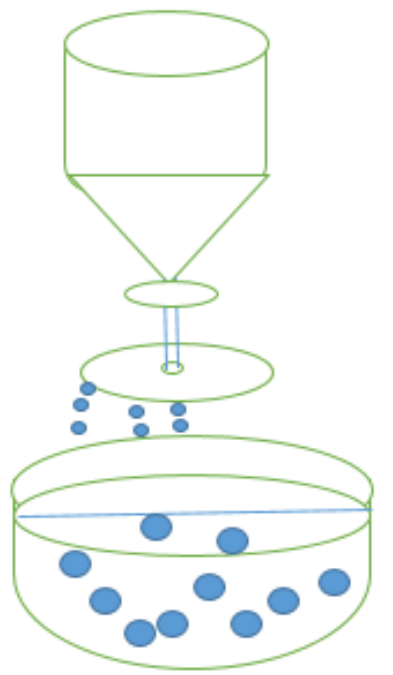

Rotative or Spinning Disk

Fig.10 Encapsulation using pan coating

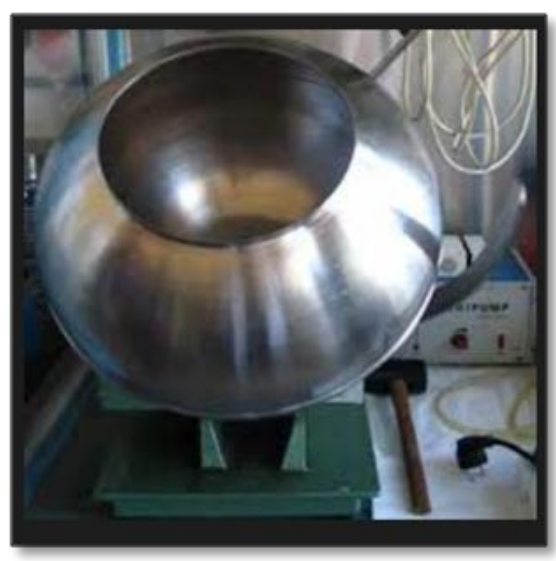


Fig.11 Applications of encapsulation (Gharsallaoui et al., 2007)

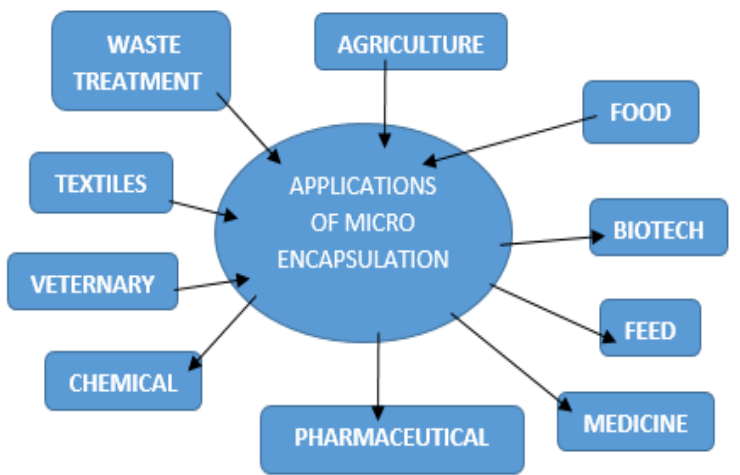

The bottom spray coating is a time consuming process as it takes long time for the formation of protective coating, the advantage in bottom spray coating is that it can be used in multilayer coating and reduced particle defects.

\section{Tangential spray fluidized bed coating}

The tangential spray fluidized bed coating consists of a tangential disc at the bottom of the coating chamber.

The disc is raised such that there is a gap between the bottom of coating chamber and the disc such that the wall material and core particles enters into the gap and get encapsulated.

\section{Spinning disk}

The encapsulation process with spinning disk is very easy and simple in operation and has high production.

The main advantage is that it saves lot of time.

In this process of encapsulation, the core materials and the wall materials are poured into a rotating disk, as the rotation of the disk continues or due to the spinning action, the core particles get coated with the protective covering.
After that the shell material is solidified by external means (generally cooling) (Dewettinck and Huyghebaert, 1998).

Research works undergone using rotating pan technique

Rotary disc atomisation for microencapsulation application- prediction of the particle trajectories (Dewettinck and Huyghebaert, 1998)

\section{Pan coating}

Pan coating is the very oldest process used in the pharmaceutical industries for manufacturing of small tablets. In the encapsulation procedure the core material is placed in the pan such that it tumbles and the wall material is applied slowly, then the temperature is gradually increased such that the solid wall material melts and will get adhered to the core material and forms a protective coating on the active material, after that it is solidified by cooling (Dewettinck and Huyghebaert, 1998).

\section{Applications of microencapsulation}

\section{Applications in food industry}

1) Improve nutritional value by adding ingredients. 2) Incorporate minerals, vitamins, 
flavors and essential oils. 3) To extend the shelf-life of food material.

\section{Limitations}

1) Additional cost. 2) Increased complexity of production process. 3) Undesirable consumer notice (visual or touch) the encapsulates in food products. 4) Stability challenges of encapsulates during processing and storage of food products.

The research in the area of microencapsulation has huge potential to resulting in superior products. This technique of microencapsulation is applicable to all industries because its application in each and every industry is unique. In agro based industries it plays an important role in the slow release of pesticides and fertilisers. It saves the flavouring compounds in spices. As there are many benefits by using microencapsulation, the research studies must be in the way of producing most economical methods as the cost of encapsulation is very high.

\section{References}

Bae E K and Lee S J 2008. Microencapsulation of avocado oil by spray drying using whey protein and maltodextrin. Journal of Microencapsulation 25(8): 549-560.

Bansode S S, Banarjee S K, Gaikwad D D, Jadhav S L and Thorat, R. M. (2010). Microencapsulation: a review. International Journal of Pharmaceutical Sciences Review and Research 1(2):38-43.

De Lara Pedroso D, Thomazini M, Heinemann R. J. B and FavaroTrindade C S. 2012. Protection of Bifidobacterium lactis and Lactobacillus acidophilus by microencapsulation using spray- chilling. International dairy journal 26(2): 127-132.

Dewettinck K and Huyghebaert A 1998. Topspray fluidized bed coating: effect of process variables on coating efficiency. LWT-Food Science and Technology 31(6): 568-575.

Estevinho B N, Rocha F, Santos L and Alves A. (2013). Microencapsulation with chitosan by spray drying for industry applications-A review. Trends in Food Science \& Technology 31(2): 138-155.

Gharsallaoui A, Roudaut G, Chambin O, Voilley A and Saurel R 2007. Applications of spray-drying in microencapsulation of food ingredients: An overview. Food Research International 40(9): 1107-1121.

Ichikawa H, Tokumitsu H, Jono $\mathrm{K}$, HUKUDA T, Osako Y and Fukumori Y 1994. Coating of pharmaceutical powders by fluidized bed process. VI. Microencapsulation using blend and composite latices of copoly (ethyl acrylate-methyl methacrylate-2hydroxyethyl methacrylate). Chemical and pharmaceutical bulletin 42(6): 1308-1314.

Ilić I, Dreu R,Burjak M, Homar M, Kerč J and Srčič S 2009. Microparticle size control and glimepiride microencapsulation using spray congealing technology. International journal of pharmaceutics 381(2): 176183.

Jyothi S S, Seethadevi A, Prabha K S, Muthuprasanna P and Pavitra P 2012. Microencapsulation: a review. International Journal of Pharma \& Bio Sciences 3:509-531.

Loksuwan and Jarunee 2007. Characteristics of microencapsulated $\beta$-carotene formed by spray drying with modified tapioca starch, native tapioca starch and maltodextrin. Food hydrocolloids 21.5: 928-935. 
Mali S D, Khochage S R., Nitalikar M M and Magdum C S. (2013). Microencapsulation: a review. Research Journal of Pharmacy and Technology 6(9): 954-961.

Saénz C, Tapia S, Chávez J and Robert P 2009. Microencapsulation by spray drying of bioactive compounds from cactus pear (Opuntiaficus-indica). Food Chemistry 114(2): 616-622.

Sheu T Y and Rosenberg M 1995. Microencapsulation by spray drying ethyl caprylate in whey protein and carbohydrate wall systems. Journal of Food Science 60(1): 98-103.
Snehal M D, Swapna K R, Manoj N M and Chandrakant M 2013. Microencapsulation: a review. Asian Journal of Research in Chemistry 6(9): 954.

Teunou E and Poncelet D 2005. Rotary disc atomization for microencapsulation applications - prediction of the particle trajectories. Journal of food engineering 71(4): 345-353.

Tonon R V, Grosso C R and Hubinger M D 2011. Influence of emulsion composition and inlet air temperature on the microencapsulation of flaxseed oil by spray drying. Food Research International 44(1): 282-289.

\section{How to cite this article:}

Saikiran, K.CH.S., Monisha Perli, N. Sreedhar Reddy and Venkatachalapathy, N. 2018. Mechanical Methods of Microencapsulation: A Review. Int.J.Curr.Microbiol.App.Sci. 7(11): 1251-1260. doi: https://doi.org/10.20546/ijcmas.2018.711.146 